\title{
Arbor
}

\section{La función del Derecho y del Juez en la Unión Europea}

\section{Gil Carlos Rodríguez Iglesias ${ }^{1}$}

Arbor CLXVII, 657 (Septiembre 2000), 57-77 pp.

Desde la creación de la Comunidad Europea del Carbón y del Acero en 1952, el Derecho ha sido un factor determinante en el proceso de integración europea. En gran medida ello ha sido posible gracias a la función conferida al juez y a este respecto me gustaría subrayar que no me refiero sólo a la función del Tribunal de Justicia de las Comunidades Europeas, sino también a la de los órganos jurisdiccionales nacionales de los Estados miembros.

El propósito del presente trabajo es tratar de explicar este fenómeno, que reposa sobre una construcción jurídica que no puede calificarse de sencilla. $^{2}$

Sucesivamente, se abordarán la función del Derecho como factor de integración económica y monetaria, los rasgos más característicos que han configurado el ordenamiento comunitario como un sistema jurídico de nuevo cuño, y los elementos básicos que configuran el poder judicial de la Unión Europea, para concluir con algunas consideraciones sobre la función del Derecho como factor de legitimación de la Unión Europea.

\section{El Derecho como factor de integración económica}

La construcción comunitaria se ha concebido como un proceso progresivo de integración económica y política de los Estados miembros, cuyos objetivos finales, sin embargo, no están definitivamente determinados ni jurídica ni políticamente ${ }^{4}$. La integración económica ha sido jurídicamente asegurada mediante las diferentes normas de Derecho comunitario en las que se ha plasmado la progresiva transferencia de competen- 


\section{Gil Carlos Rodriguez Iglesias}

cias realizada por los Estados miembros en favor de las Comunidades Europeas en los tres núcleos básicos de la política económica, a saber: asignación de recursos, redistribución de la riqueza y mantenimiento de la estabilidad macroeconómica.

La transferencia competencial en el ámbito de la asignación de recursos se ha plasmado en la normas relativas al mercado común o mercado interior y en las distintas políticas comunitarias. Las disposiciones sobre cohesión económica y social reflejan la asunción de competencias por las instituciones comunitarias en relación a la función económica de redistribución de la riqueza y, por último, la transferencia de competencias en el ámbito macroeconómico está en la base de la Unión Económica y Monetaria. Ahora bien, no ha existido paralelismo en la transferencia del ejercicio de competencias a las Comunidades Europeas en estas tres funciones de la política económica, porque los tratados constitutivos ofrecieron inicialmente fundamento jurídico sólido y claro sólo para la creación del mercado común y algunas políticas comunitarias, siendo necesario esperar a las reformas de los mismos operadas por el Acta Única Europea (1987) y el Tratado de Maastricht (1993) para contar con un fundamento "constitucional" en los tratados respecto a las normas de Cohesión Económica y Social y a las de Unión Económica y Monetaria. El reflejo de esta progresiva integración en las tres funciones de la política económica se encuentra en el artículo 2 del Tratado UE cuando señala que el objetivo primordial de la Unión, consistente en "promover un progreso económico y social equilibrado y sostenible», se realizará mediante tres medios claramente determinados: "la creación de un espacio sin fronteras interiores (mercado interior), el fortalecimiento de la cohesión económica y social y el establecimiento de una unión económica y monetaria (...)». El Derecho comunitario originario (es decir, los Tratados constitutivos) y las normas de Derecho derivado (es decir, las normas adoptadas sobre la base de los Tratados constitutivos) tienen distinto alcance en estos tres ámbitos y prevén la utilización de técnicas jurídicas diferentes para realizar y proteger la transferencia de competencias por parte de los Estados miembros. Como consecuencia de ello, la función desempeñada por el Derecho como instrumento de integración económica y monetaria varía considerablemente en las tres vertientes principales del proceso de integración.

El Tratado CEE preveía el establecimiento progresivo del mercado común a lo largo de un período de transición de doce años, que concluía el 31 de diciembre de 1969. En esta última fecha no se pudo establecer de forma completa el mercado común y el renovado compromiso político de los Estados con este objetivo les llevó a reformar el Tratado CEE con el Acta Única Europea, introducir la noción de mercado interior y fijar el 


\section{La función del Derecho y del Juez en la Unión Europea}

31 de diciembre de 1992 como fecha para su realización, reforzando para ello los mecanismos jurídicos del Tratado CEE.

El Tratado CEE no definía directamente la noción de mercado común, si bien su significado se podía inferir de las disposiciones que lo regulaban. Así, el Tribunal de Justicia dijo que: «la noción de mercado común, delimitada por una reiterada jurisprudencia, comprende la eliminación de todas las trabas a los intercambios intracomunitarios con vistas a la fusión de los mercados nacionales en un mercado único que funcione en condiciones lo más similares posible a las de un verdadero mercado interior». Entre estas disposiciones destacaban las referentes a las libertades de circulación de los factores productivos. El Acta Única Europea crea la noción de mercado interior, señalando que el mismo «implicará un espacio sin fronteras interiores en el que la libre circulación de mercancías, personas, servicios y capitales estarán garantizadas de acuerdo con las disposiciones del presente Tratado». Este nuevo concepto de mercado interior coincide básicamente con el de mercado común, aunque es más limitado, porque afecta sólo a las libertades, y más profundo, porque incluye la eliminación de las fronteras físicas entre los Estados.

Esencialmente el establecimiento del mercado común y del mercado interior lleva consigo la realización de las libertades de circulación de mercancías, personas, servicios y capitales, así como un régimen de competencia leal, una política comercial común frente al exterior y la instauración de políticas comunes en algunos sectores económicos. El Tratado CEE preveía una amplia panoplia de técnicas jurídicas para la consecución del mercado común y del mercado interior:

- Técnica negativa: prohibición de los obstáculos a la libre circulación de los factores productivos, que suponen discriminación por razón de la nacionalidad o el lugar de residencia, o que dificultan el libre comercio entre los Estados miembros.

- Técnica positiva: armonización de las legislaciones nacionales divergentes.

- El reconocimiento mutuo como alternativa a la armonización.

- Técnica preventiva: procedimientos de control previo en materia de obstáculos técnicos y ayudas de Estado.

Además, los preceptos del Tratado CEE relativos al mercado común y al mercado interior preveían su desarrollo mediante actos normativos dotados de obligatoriedad jurídica.

Esta estricta articulación de los instrumentos jurídicos se ha visto potenciada por la interpretación de los mismos desarrollada por el Tribunal 


\section{Gil Carlos Rodríguez Iglesias}

de Justicia. En efecto, el Tribunal de Justicia consideró que el final del período transitorio era la fecha límite para la entrada en vigor de las disposiciones previstas para la instauración del mercado común y, consecuentemente con ello, reconoció el efecto directo de la mayor parte de los preceptos del Tratado CEE que prohibían los obstáculos a las libertades de circulación, pese a que no se habían adoptado todas las normas de desarrollo de las mismas. La jurisprudencia además consagró una interpretación amplia de las libertades económicas reconocidas por el Tratado CEE.

Así, el Tribunal de Justicia ha afirmado, en relación con la libre circulación de mercancías, que cualquier producto legalmente comercializado en un Estado miembro debe circular sin obstáculos en todo el mercado común, es decir, sin necesidad de cumplir los requisitos establecidos por la legislación nacional del Estado de importación, a menos que tal Estado pueda invocar razones imperativas de interés general (protección de la salud pública o del medio ambiente, por ejemplo) que justifiquen el obstáculo en cuestión. Por ejemplo, en su sentencia sobre la ley alemana de la cerveza, el Tribunal de Justicia consideró que las cervezas producidas y comercializadas en otros Estados miembros podían ser comercializadas en Alemania, aunque no cumplieran con las normas alemanas relativas a la "pureza» de la cerveza, ${ }^{5}$ que databan del siglo XVI, que eran de obligatorio cumplimiento para los productores alemanes. Alemania no había demostrado que tal legislación, que obstaculizaba la importación de casi todas las cervezas no producidas en Alemania, era necesaria para proteger al consumidor o la salud pública. Esta jurisprudencia ha supuesto una reducción considerable de la necesidad de armonizar las legislaciones nacionales en orden a la realización de la libre circulación de mercancías.

De igual manera, en cuanto a la libertad de establecimiento en otro Estado miembro y a la libre prestación de servicios transfronteriza, ya en 1974 el Tribunal de Justicia decidió, en sus sentencias en los asuntos Reyners $^{6}$ y Walrave W $^{7}$ que tales libertades no sólo se refieren a medidas adoptadas en el ámbito económico, en las que las personas o las empresas que desean establecerse o prestar servicios son consideradas factores de producción, sino que deben ser interpretados como auténticas libertades fundamentales del ciudadano de los Estados miembros, subrayando el Tribunal de Justicia en la sentencia Walrave que se trata de derechos que los jueces nacionales están obligados a tutelar. Además, el Tribunal de Justicia ha considerado que tales libertades van más allá del simple trato no discriminatorio respecto a los nacionales de otros Estados miembros, de manera que, por ejemplo, una empresa no siempre 


\section{La función del Derecho y del Juez en la Unión Europea}

está obligada a respetar toda la normativa de un Estado miembrc en el que sólo presta temporalmente servicios, a no ser que tal legislación esté justificada por razones de interés general y que tales intereses no estén ya salvaguardados por la normativa del Estado en que la empresa está establecida.

Además, las libertades del mercado interior se van desvinculando poco a poco de su vertiente puramente económica. Buen ejemplo es la jurisprudencia que incluye en el campo de aplicación del Tratado CE a los destinatarios de servicios -entre los que se incluyen los turistas-, lo que ha dado una gran potencialidad a las libertades consagradas en el mismo. ${ }^{8}$ De esta manera el principio de no discriminación se ha generalizado en la jurisprudencia y se ha desvinculado prácticamente de la prueba del ejercicio de una actividad económica concreta.

Esta evolución ha culminado con la creación de una ciudadanía europea, consagrada por el Tratado de Maastricht, que modifica en este punto el Tratado CE, que viene a complementar la ciudadanía de los Estados miembros. Aparte del derecho a no sufrir discriminaciones en razón de la nacionalidad, esta ciudadanía comporta el derecho a circular y residir libremente en otro Estado miembro y el derecho de sufragio activo y pasivo en elecciones locales y europeas. El Tribunal de Justicia ha tenido que pronunciarse por primera vez sobre las disposiciones relativas a la ciudadanía europea en su sentencia Martínez Sala ${ }^{9}$. El Tribunal de Justicia afirmó que la Sra. Martínez Sala, de nacionalidad española, había sido objeto en Alemania de una discriminación contraria al Tratado CE, que atribuye a la condición de ciudadano de la Unión los derechos y deberes previstos por el Tratado CE, entre ellos el de no sufrir discriminación por razón de la nacionalidad en el ámbito de aplicación ratione materiae del Tratado CE (en el caso concreto se trataba del acceso a determinadas prestaciones de asistencia social).

Como puede apreciarse, el Derecho ha constituido un instrumento de enorme utilidad en la realización del mercado común y del mercado interior. Ello se debe a que la firme voluntad política de alcanzar estos objetivos económicos llevó a los Estados a elaborar una completa articulación de mecanismos jurídicos para provocar y proteger la necesaria transferencia de competencias de los Estados a las instituciones comunitarias. De esta manera ha hecho avanzar el mercado común en momentos en los que la voluntad política de los Estados se había debilitado (como ocurrió durante los años setenta) y la utilización de la armonización de legislaciones se hacía especialmente difícil.

Al contrario, el Tratado CEE no recogió la reducción de los desequilibrios regionales como uno de los objetivos económicos de la Comunidad, 


\section{Gil Carlos Rodríguez Iglesias}

pero la adhesión de nuevos Estados con un nivel inferior de desarrollo económico provocó la creación de una dispersa, incoherente y poco estructurada Política Regional Comunitaria, que el Acta Única Europea transformó en la llamada cohesión económica y social. En efecto, el Acta Única Europea constitucionalizó el objetivo de la cohesión económica y social, realizando de forma implícita una especificación del contenido de los objetivos de la Comunidad el equiparar el objetivo de la cohesión a los del mercado común y la aproximación de la políticas económicas de los Estados miembros ${ }^{10}$.

Ahora bien, la configuración jurídica de la cohesión económica y social es mucho más débil que la establecida en relación al mercado común. En primer lugar, no se da una definición clara del concepto de cohesión económica y social ni en el Derecho originario ni en el derivado, ya que el Tratado CE sólo establece el mandato genérico de desarrollar y proseguir la acción de refuerzo de la cohesión, que es circunscrita seguidamente a la reducción de las diferencias entre los niveles de desarrollo de las regiones y a la reducción del retraso de las menos favorecidas. En segundo lugar, no se establecen en el Tratado CE unas condiciones y un ritmo para la reducción de esos desequilibrios regionales. No se cuantifican los objetivos a conseguir ni se determinan etapas y fechas concretas para alcanzarlos, así como tampoco se prevén mecanismos de control y vigilancia del respeto del objetivo de la cohesión. Por último, el Tratado CE prevé los medios o técnicas jurídicas utilizables para lograr el objetivo de la cohesión, a saber: la intervención financiera estructural, la formulación de las políticas comunitarias y el desarrollo del mercado interior teniendo en cuenta los elementos de cohesión, y la consideración del objetivo de la cohesión en la conducción y coordinación de las políticas económicas nacionales. El Tratado CE prima la utilización de la intervención financiera a través de los fondos estructurales y otros instrumentos con finalidad estructural. Las técnicas jurídicas previstas tienen por lo tanto una marcada dependencia de la voluntad política de los Estados miembros y el Tribunal de Justicia difícilmente podrá contribuir a su aplicación cuando dicha voluntad política se debilite.

La articulación jurídica de la cohesión económica y social ha sido constitucionalizada de forma deficiente, ya que no se establece una verdadera transferencia de competencias de los Estados en favor de las instituciones comunitarias para la eliminación de los desequilibrios regionales, amparada y protegida por unos mecanismos jurídicos eficaces. Ello obedece a la ausencia de una firme voluntad política de los Estados de conferir a la Comunidad un papel determinante para la redistribución de 


\section{La función del Derecho y del Juez en la Unión Europea}

la riqueza entre las diferentes regiones del territorio comunitario. Mientras esta situación no se modifique, no parece factible una transformación radical de las normas de cohesión, que conlleve una transferencia significativa de competencias a las instituciones comunitarias. Por tanto, la función del Derecho como instrumento para la eliminación de los desequilibrios regionales ha sido bastante limitada, si bien la importancia de la constitucionalización del objetivo de la cohesión económica y social no puede ser subestimada.

En el ámbito económico y monetario, el Tratado CEE no previó inicialmente más que una coordinación de las políticas nacionales. Sin embargo, el desarrollo del proceso de integración mostró rápidamente la insuficiencia de esta técnica jurídica para resolver los problemas monetarios de la Comunidad Económica Europea. La reacción de los Estados miembros fue la elaboración de un plan, en los años 70, para la creación por etapas de una Unión Económica y Monetaria. Pero este proyecto no se "constitucionalizó» ni se plasmó en normas claramente obligatorias para los Estados. Esta opción reflejaba la ausencia de voluntad política de los Estados para transferir el ejercicio de competencias a las instituciones comunitarias en ámbitos tan vinculados a la soberanía como el económico y el monetario.

El Tratado de Maastricht, que modifica en este punto el Tratado CE, consagra una vía completamente diferente para estructurar la intervención comunitaria en el ámbito económico y monetario, a saber: la constitucionalización del objetivo y del método de realización de la Unión Económica y Monetaria. El Tratado CE contiene ahora más claramente principios de política económica, que podrían considerarse como la "constitución económica" de la Comunidad, como el de una economía de mercado abierta y de libre competencia, que favorezca una eficiente asignación de recursos. Pero el cambio principal es que el Tratado de Maastricht ha optado por la transferencia de competencias de los Estados a las instituciones comunitarias, consagrada jurídicamente, como medio para conseguir la Unión Económica y Monetaria. Esta opción refleja la firme voluntad política de casi todos los Estados miembros respecto al proyecto de Unión Económica y Monetaria.

La Unión Económica y Monetaria se concibió como un plan por etapas perfectamente definidas, que concluyó el 1 de enero de 1999, fecha irreversible de inicio de la fase final de la Unión Económica y Monetaria, con una política monetaria común y una estrecha coordinación de las políticas económicas nacionales. Además de la determinación de los plazos y de las condiciones jurídicas y económicas mínimas, el Tratado CE articula de forma bastante completa los instrumentos jurídicos que de- 


\section{Gil Carlos Rodríguez Iglesias}

berán utilizarse en la puesta en práctica del plan de Unión Económica y Monetaria y determina los objetivos finales a conseguir. Esta articulación precisa del plan de la Unión Económica y Monetaria y, en particular, la determinación de una fecha imperativa, sin duda ha coadyuvado al mantenimiento del compromiso político de los Estados con este objetivo económico en situaciones de crisis susceptibles de debilitar la percepción favorable de la Unión Económica y Monetaria existente en el momento de redacción del Tratado de Maastricht.

Posiblemente, el aspecto que puede presentar más problemas es la asimetría entre la configuración de la Unión Económica, en la que no se produce transferencia de competencias, sino coordinación de las políticas económicas de los Estados miembros (que se traduce en un procedimiento de control y ciertas normas de disciplina financiera y presupuestaria, en particular respecto a la limitación de los déficits públicos excesivos), y la de la Unión Monetaria, que conlleva una transferencia completa de competencias en favor de la Comunidad Europea. Los Estados miembros consideraron precaria la articulación jurídica de la vertiente económica de la Unión Económica y Monetaria, percibida con desasosiego por algunos Estados miembros como Alemania, y han impulsado la adopción de normas de Derecho derivado destinadas a reforzar los instrumentos jurídicos inicialmente establecidos ${ }^{11}$. Esta precariedad inicial se ha mitigado mediante la adopción por el Consejo Europeo de Amsterdam de junio de 1997 del llamado Pacto de Estabilidad y Crecimiento (PEC), formado por una Resolución del Consejo Europeo de 17 de junio de 1997, ${ }^{12}$ por el Reglamento 1466/97, relativo al refuerzo de la supervisión de las situaciones presupuestarias y la supervisión y coordinación de las políticas económica, ${ }^{13}$ y por el Reglamento 1467/97, relativo a la aceleración y clarificación del procedimiento de déficit excesivo. ${ }^{14}$

Ahora bien, la regulación constitucional de la Unión Económica y Monetaria tiene algunos elementos que, desde un punto de vista jurídico, pueden distorsionar u obstaculizar su aplicación. Entre los mismos destacan las situaciones especiales de Dinamarca y el Reino Unido y la relativa contradicción o, al menos, problemática armonización de las normas imperativas sobre plazos con las disposiciones sobre los criterios de convergencia económica necesarios para la adopción de la moneda única. Estos obstáculos reflejan la existencia de fisuras en la voluntad política de los Estados con relación a la realización de la Unión Económica y Monetaria y la existencia de concepciones económicas diferentes de la misma, que se proyectan en el Tratado CE en forma de soluciones de compromiso, cuya aplicación puede resultar difícil. 


\section{La función del Derecho y del Juez en la Unión Europea}

\section{El desarrollo de un sistema jurídico de nuevo cuño}

La originalidad del Derecho comunitario en relación con los modelos tradicionales que proporcionan el Derecho internacional y el ordenamiento interno de los Estados se basa sobre todo en tres factores: la estructura institucional de la Comunidad, el sistema de fuentes del Derecho y la intensidad de las relaciones entre el Derecho comunitario y el Derecho interno de los Estados. Es en este último ámbito en el que el Tribunal de Justicia ha consagrado algunos principios básicos que son generalmente considerados como los mas característicos del ordenamiento jurídico comunitario: se trata de los principios del efecto directo y de la primacía, a los que hay que añadir más recientemente el principio de la responsabilidad del Estado por daños causados a los particulares como consecuencia de la violación del Derecho comunitario. Me referiré seguidamente a cada uno de estos principios.

El principio del efecto directo ha sido considerablemente desarrollado y matizado, pero su contenido esencial, identificado en la sentencia Van Gend en Loos, de $1963,{ }^{15}$ radica en la posibilidad de que los particulares invoquen ante los tribunales nacionales los derechos que les confieren las normas comunitarias sin ningún elemento complementario de Derecho interno, a condición de que dichas normas sean suficientemente precisas e incondicionales. En esta sentencia el Tribunal de Justicia caracterizó de forma expresa al Derecho comunitario como «un nuevo ordenamiento jurídico de derecho internacional».

El efecto directo de las normas comunitarias no es, por consiguiente, una mera técnica de inserción en el ordenamiento interno, sino que es el resultado de una concepción del Derecho comunitario como un ordenamiento cuyos sujetos no son solamente los Estados, sino también los particulares, titulares de situaciones jurídicas subjetivas - derechos y obligaciones - creadas directamente por el ordenamiento jurídico comunitario. Esta concepción es la que está en la base de la doctrina jurisprudencial del efecto directo, que el Tribunal de Justicia suele caracterizar señalando a propósito de las normas dotadas de tal efecto que éstas «crean derechos subjetivos que los órganos jurisdiccionales nacionales deben salvaguardar».

La coexistencia en un mismo ámbito territorial del ordenamiento jurídico comunitario y del ordenamiento jurídico de cada uno de los Estados miembros da lugar a la aparición de conflictos entre las normas de uno y otro ordenamiento. De acuerdo con la jurisprudencia del Tribunal de Justicia, estos conflictos han de resolverse por aplicación del principio de la primacía del Derecho comunitario sobre el Derecho interno, consagrado 


\section{Gil Carlos Rodríguez Iglesias}

fundamentalmente por la sentencia Costa / Enel ${ }^{16}$ y precisado por la sentencia Simmenthal ${ }^{17}$.

La afirmación jurisprudencial de la primacía del Derecho comunitario se basa fundamentalmente en los siguientes argumentos: en primer lugar, en los caracteres y objetivos de las Comunidades Europeas, a las cuales los Estados han transferido determinadas competencias que llevan consigo la consiguiente limitación de la competencia estatal; en segundo lugar, en el carácter obligatorio y directamente aplicable de los Reglamentos comunitarios conforme al texto del Tratado $\mathrm{CE}$ lo que carecería de sentido si esa eficacia pudiera ser unilateralmente anulada por los Estados miembros; en tercer lugar, en la obligación de los Estados miembros de abstenerse de cualquier medida susceptible de poner en peligro la realización de los objetivos comunitarios.

El Tribunal de Justicia dedujo del principio de primacía la obligación de todo juez nacional de aplicar, en el marco de su competencia, íntegramente el Derecho comunitario y de proteger los derechos que éste confiere a los particulares, dejando sin aplicación toda disposición eventualmente contraria de la ley nacional, ya sea ésta anterior o posterior a la norma comunitaria.

Naturalmente la efectividad del principio de primacía consagrado por la jurisprudencia del Tribunal de Justicia depende de su puesta en práctica por parte de los órganos jurisdiccionales nacionales, ante los cuales se suscitan los conflictos concretos entre normas de Derecho interno y normas comunitarias. En términos muy generales, cabe observar que la mayor parte de los tribunales nacionales han respetado los criterios consagrados por la jurisprudencia del Tribunal de Justicia. Ha habido, ciertamente, algunas excepciones notorias, pero en la mayoría de los casos los conflictos entre la jurisprudencia de algunos tribunales nacionales y la del Tribunal de Justicia se han solucionado sobre la base de un alineamiento de los primeros en relación con el segundo, pudiéndose apreciar recientemente una convergencia cada vez más acentuada.

Junto a los principios tradicionales de efecto directo y primacía, la jurisprudencia más reciente ha consagrado el principio de la responsabilidad del Estado por daños causados a los particulares como consecuencia de la violación del Derecho comunitario.

Este principio fue claramente reconocido en la sentencia Francovich, de $1991^{18}$. Esta sentencia resolvió cuestiones prejudiciales planteadas por dos órganos jurisdiccionales italianos en un contexto procesal caracterizado por la no adopción por parte de Italia de la legislación necesaria para dar cumplimiento a una Directiva comunitaria que prevé determinadas garantías para los trabajadores en caso de insolvencia del empresario. El Tri- 


\section{La función del Derecho y del Juez en la Unión Europea}

bunal de Justicia, después de concluir que las disposiciones de la Directiva que reconocen los derechos de los trabajadores no pueden ser consideradas como normas de efecto directo, entró a examinar la cuestión dirigida a saber si, en tales condiciones, el Estado estaba obligado a reparar los daños que para los trabajadores resultaban de la aludida omisión. El Tribunal de Justicia afirmó la existencia de un principio general de responsabilidad del Estado sobre la base de una argumentación en la que cabe destacar, en particular, el menoscabo de la plena eficacia de las normas comunitarias y de los derechos que éstas reconocen si los particulares no tuvieran la posibilidad de obtener reparación cuando tales derechos son lesionados por una violación del Derecho comunitario imputable a un Estado, y la obligación de los Estados miembros de adoptar todas las medidas generales o particulares apropiadas para asegurar el cumplimiento de las obligaciones que les incumben, obligación que les impone expresamente el artículo 10 (ex artículo 5) del Tratado CE y que incluye el deber de eliminar las consecuencias ilícitas de una violación del Derecho comunitario.

Este principio es desarrollado en otras sentencias posteriores, en particular en la sentencia Brasserie du Pêcheur y Factortame III. ${ }^{19}$ En esta sentencia, relativa entre otras cosas a los derechos de empresas pesqueras españolas que se habían establecido en el Reino Unido y habían sufrido un trato discriminatorio, el Tribunal de Justicia confirma que el Estado responde también por las violaciones de Derecho comunitario atribuibles al legislador nacional. Para que la violación sea «suficientemente caracterizada" y dé lugar a responsabilidad, el criterio decisivo es el de la inobservancia manifiesta y grave de los límites impuestos a su facultad de apreciación: para ello el juez debe considerar el grado de claridad y de precisión de la norma vulnerada, la amplitud del margen de apreciación, el carácter intencional o involuntario de un eventual error de Derecho, así como su carácter excusable o inexcusable.

El principio de responsabilidad del Estado constituye, por una parte, un elemento que refuerza decisivamente la protección de los derechos conferidos a los particulares por las normas comunitarias y, por otra, es un factor que puede contribuir a un cumplimiento más diligente de las normas comunitarias por parte de los Estados miembros toda vez que los incumplimientos son ahora susceptibles de dar lugar a obligaciones de reparación que en algunos casos serán sumamente gravosas para el tesoro público.

Todos estos principios implican una articulación del Derecho comunitario y del Derecho interno que alcanza un grado de intensidad sin precedente en las relaciones entre el clásico Derecho internacional y el Derecho interno de los Estados. La intensidad de la inserción del Derecho 


\section{Gil Carlos Rodríguez Iglesias}

comunitario en el orden interno choca con concepciones dogmáticas profundamente ancladas en algunos sistemas jurídicos nacionales. Para poner simplemente algunos ejemplos, me gustaría destacar como el efecto directo resulta especialmente difícil de asimilar a partir de una concepción de los ordenamientos internacional y interno en términos de separación total (dualismo). La primacía del Derecho comunitario lleva a cuestionar la jerarquía normativa tradicional y la responsabilidad del Estado supone una modificación sensible en relación con los regímenes tradicionales de la responsabilidad de los poderes públicos que existen en muchos Estados miembros.

Tanto el efecto directo como la responsabilidad patrimonial de los Estados derivan de una concepción del Derecho comunitario como un ordenamiento cuyos sujetos son también los particulares. Han sido precisamente los particulares, a través de sus acciones antes órganos jurisdiccionales, los que han hecho avanzar el proceso de construcción de una Comunidad de derecho y el proceso de integración europea tal y como hoy lo conocemos. Además, el ámbito de aplicación de las libertades del mercado interior se ha ido ampliando, y el Derecho comunitario se ha ido poco a poco desvinculando de su componente puramente económica.

\section{El poder judicial en la Unión europea}

La Unión Europea, que no es un Estado, y que tiene una estructura institucional que se aparta del modelo del Estado, no puede ser explicada a la luz de la clásica división de poderes de Montesquieu: el Parlamento Europeo no dispone de las competencias plenas del poder legislativo, el Consejo es una institución híbrida entre el ejecutivo y el legislativo, la Comisión es un órgano que no puede ser asimilado a un gobierno, etc. En cambio, en la Comunidad Europea existe un auténtico poder judicial, constituido por órganos jurisdiccionales independientes encargados de las mismas funciones que corresponden al poder judicial dentro de un Estado. ${ }^{20}$

De acuerdo con el artículo 220 (ex artículo 164) del Tratado CE, el Tribunal de Justicia tiene la misión de garantizar el respeto del Derecho en la interpretación y aplicación del Tratado. Ahora bien, esta función no corresponde con carácter exclusivo al Tribunal de Justicia, sino que éste la comparte no solamente con el nuevo órgano jurisdiccional comunitario existente desde 1989 - el Tribunal de Primera Instancia de las Comunidades Europeas - sino además y sobre todo con los órganos jurisdiccionales del conjunto de los Estados miembros. 


\section{La función del Derecho y del Juez en la Unión Europea}

En efecto, cabe afirmar que, desde sus orígenes, la Comunidad Europea ha estado organizada en el ámbito judicial sobre la base del llamado principio de subsidiariedad - principio que sólo ha sido previsto por el Tratado de Maastricht- en el sentido de que sólo se ha reservado al órgano jurisdiccional propio de la Comunidad el mínimo de competencias que no podían ser atribuidas a los órganos jurisdiccionales nacionales. De este modo el poder judicial en la Comunidad Europea aparece distribuido entre los órganos jurisdiccionales propios de la Comunidad, esto es el Tribunal de Justicia y, más recientemente, el Tribunal de Primera Instancia, y los órganos jurisdiccionales nacionales. Son estos órganos jurisdiccionales nacionales los que, de forma congruente con la ejecución administrativa preferentemente descentralizada del Derecho comunitario, están encargados de aplicar el Derecho comunitario en su ámbito de competencia territorial y funcional.

Algunas de las competencias del Tribunal de Justicia han sido transferidas al Tribunal de Primera Instancia de las Comunidades Europeas creado por decisión del Consejo de 24 de octubre de $1988 .{ }^{21}$ La creación de este Tribunal ha perseguido la doble finalidad de mejorar la protección judicial para los recursos que requieren un examen profundo de hechos complejos y de permitir que el Tribunal de Justicia se concentre en su labor esencial, que es la de velar por la interpretación uniforme del Derecho comunitario. El Tribunal de Primera Instancia es actualmente competente para conocer en primera instancia de todos los recursos interpuestos por particulares (personas físicas y jurídicas). Las resoluciones del Tribunal de Primera Instancia pueden ser recurridas en casación ante el Tribunal de Justicia.

A continuación, haré algunas observaciones sobre los aspectos de la competencia del Tribunal de Justicia que me parecen más significativos: el control jurisdiccional de los incumplimientos de Estado, el control de la legalidad comunitaria y la competencia prejudicial.

Los procesos dirigidos a obtener la declaración judicial de un incumplimiento de Estado se inician sobre la base de recursos presentados por la Comisión o por un Estado miembro. De ordinario, los Estados prefieren solucionar sus diferencias por vías políticas, por lo que la iniciación de un proceso judicial en el que un Estado miembro demanda a otro por incumplimiento de sus obligaciones es algo excepcional. Hasta ahora sólo en dos ocasiones llegó el Tribunal de Justicia a dictar una sentencia en un litigio de este tipo. ${ }^{22}$ Son, en cambio, frecuentes los procesos por incumplimiento promovidos por la Comisión en cumplimiento de su misión de velar por la aplicación del Derecho comunitario. 


\section{Gil Carlos Rodríguez Iglesias}

La declaración judicial de la existencia de un incumplimiento obliga al Estado interesado a adoptar las medidas necesarias para la ejecución de la sentencia. No existen, en cambio, medios de ejecución forzosa de las sentencias dictadas en proceso de incumplimiento, pero desde la entrada en vigor del Tratado de Maastricht si un Estado no ha adoptado las medidas suficientes para ejecutar una sentencia que ha declarado su incumplimiento, la Comisión está facultada para someter el asunto al Tribunal de Justicia, que podrá imponer al Estado afectado el pago de una suma a tanto alzado o de una multa coercitiva.

El control jurisdiccional de la legalidad comunitaria constituye asimismo un aspecto esencial de la función del Tribunal de Justicia. La expresión "control de la legalidad" debe ser entendida en un sentido amplio. De un lado, dicha expresión cubre tanto un control de la legalidad en sentido estricto - es decir de la conformidad de los actos comparables a los actos administrativos nacionales con las normas que les sirven de fundamento - como un control de constitucionalidad, que tiene por objeto revisar la conformidad de los actos normativos de carácter general con los tratados constitutivos, tratados que, no obstante su naturaleza jurídico-formal de instrumentos internacionales, han sido interpretados y aplicados por el Tribunal de Justicia como una auténtica Constitución comunitaria. En este sentido cabe recordar que en distintas ocasiones el Tribunal de Justicia ha caracterizado al Tratado CE como la «Carta constitucional de una comunidad de derecho». ${ }^{23}$

De otro lado, la noción de legalidad comunitaria no sólo incluye el respeto de las normas escritas, sino también de los principios generales de Derecho, que comprenden en particular los principios generales comunes a los sistemas jurídicos de los Estados miembros, que el Tribunal de Justicia considera aplicables con carácter general en el ámbito del ordenamiento comunitario, por ejemplo en materia de derechos fundamentales de la persona.

El control de la legalidad comunitaria se efectúa sobre la base de una pluralidad de vías procesales: el recurso de nulidad o de anulación, el recurso por omisión, el control incidental de legalidad de actos normativos generales, el examen prejudicial de validez de los actos e incluso las acciones indemnizatorias, que, si bien tienen por objeto la declaración y determinación de la responsabilidad extracontractual de la Comunidad, también dan lugar al control de la legalidad de los actos u omisiones que generan el daño.

La competencia prejudicial atribuida al Tribunal de Justicia para interpretar el Derecho comunitario y apreciar la validez de los actos de las instituciones comunitarias constituye quizás el elemento más impor- 


\section{La función del Derecho y del Juez en la Unión Europea}

tante del conjunto del sistema judicial comunitario. Como ya he indicado, son los órganos jurisdiccionales nacionales los que, de forma congruente con la ejecución administrativa preferentemente descentralizada del Derecho comunitario, están encargados de aplicar el Derecho comunitario en su ámbito de competencia territorial y funcional. Es evidente que la descentralización de la aplicación del Derecho comunitario europeo lleva consigo un riesgo potencial para la uniformidad de la interpretación de las normas comunes, que debe insertarse en un tejido normativo que aglutina y engloba quince tradiciones jurídicas diferentes.

El desarrollo del ordenamiento jurídico comunitario es fruto, en gran medida, de la colaboración establecida entre el Tribunal de Justicia de las Comunidades Europeas y los jueces nacionales, a través del procedimiento prejudicial previsto en el artículo 234 (ex artículo 177) del Tratado CE y en las correspondientes disposiciones de los Tratados CECA y CEEA. En el proceso prejudicial pueden presentar observaciones escritas y orales no solamente las partes en el proceso principal, sino también todos los Estados miembros, así como la Comisión de las Comunidades Europeas. También el Consejo y el Parlamento, cuando se discuta la validez de uno de sus actos.

La relación entre el Tribunal de Justicia y los órganos jurisdiccionales nacionales es una relación de cooperación y no de jerarquía. Ciertamente las sentencias prejudiciales son vinculantes para los órganos jurisdiccionales nacionales y éstos, en la medida en que sus decisiones no son susceptibles de ulterior recurso de Derecho interno -o en la medida en que se enfrentan con un problema de validez de un acto comunitarioestán obligados a plantear cuestión prejudicial al Tribunal de Justicia.

No cabe desconocer a este respecto el hecho de que los jueces nacionales ejercen su función de juez comunitario en cuanto jueces nacionales. Quiero decir con esto que la actuación de los órganos jurisdiccionales nacionales se efectúa en el marco de las reglas de organización y de procedimiento del Derecho interno. Eso sí, el Derecho comunitario establece unas garantías mínimas que tales procedimiento nacionales deben cumplir para ser compatibles con el Derecho comunitario. Las modalidades procedimentales no pueden ser menos favorables que las relativas a recursos similares de naturaleza interna (principio de equivalencia) y no pueden conducir a que el ejercicio de los derechos conferidos por el ordenamiento jurídico comunitario resulte prácticamente imposible o excesivamente difícil (principio de efectividad). Como consecuencia de tal principio, por ejemplo, toda decisión que aplique el Derecho comunitario debe ser susceptible de un control jurisdiccional. El denominado «derecho al juez» es un principio esencial en una Comunidad 
de derecho. Las sentencias paradigmáticas son las de los asuntos Johnston, de $1986,{ }^{24}$ y Heylens, de $1987 .{ }^{25}$

En la sentencia en el asunto Heylens el Tribunal de Justicia destacó este aspecto de la tutela judicial, en tanto que principio general del Derecho que se deriva de las tradiciones constitucionales comunes a los Estados miembros y que se ve sancionado en los artículos 6 y 13 del Convenio Europeo de los Derechos Humanos. En esta sentencia el Tribunal de Justicia extiende la protección de tal derecho fundamental a la obligación de comunicar los motivos de toda decisión administrativa, en cuanto que de ella depende la eficacia del control jurisdiccional.

Pero el ejemplo más espectacular del establecimiento de unas garantías mínimas es probablemente el de la tutela judicial cautelar. ${ }^{26}$

En la sentencia Factortame I, de 19 de junio de $1990^{27}$, el Tribunal de Justicia reconoce a los tribunales internos la competencia para suspender cautelarmente los efectos de un acto interno con fuerza de ley, presuntamente contrario al ordenamiento comunitario, mientras se tramita ante el Tribunal de Justicia la correspondiente cuestión prejudicial. El Tribunal de Justicia no pudo ser más explícito al estimar que el efecto útil del sistema de remisión prejudicial se debilitaría y «la plena eficacia del Derecho comunitario se vería igualmente reducida si una norma de Derecho nacional pudiera impedir al juez, que conoce de un litigio regido por el Derecho comunitario, conceder medidas provisionales para garantizar la plena eficacia de la resolución prejudicial que debe recaer acerca de los derechos invocados con base en el Derecho comunitario".

Es más, en la sentencia Zuckerfabrik ${ }^{28}$, de 1991, el Tribunal de Justicia admitió la posibilidad de que los tribunales nacionales suspendan cautelarmente los efectos de un acto interno, adoptado en aplicación de una norma comunitaria presuntamente inválida. A este respecto las exigencias de una tutela judicial efectiva prevalecen, al menos provisionalmente, sobre el monopolio del Tribunal de Justicia para pronunciarse acerca de la validez de los actos comunitarios.

En definitiva, se trata de garantizar la plena eficacia de le decisión jurisdiccional que debe decidir sobre la existencia de los derechos invocados sobre la base del Derecho comunitario, pues, en palabras del Tribunal Supremo español, «la necesidad del proceso para obtener razón no debe convertirse en un daño para el que tiene la razón». ${ }^{29}$

Se pueden concluir estas breves reflexiones sobre el poder judicial en la Unión Europea señalando que el Tribunal de Justicia ha podido aportar su decisiva contribución a la consolidación del proceso de integración gracias a una sólida posición institucional que no puede ser plenamente encuadrada en ninguno de los modelos jurisdiccionales tradicionales, del 


\section{La función del Derecho y del Juez en la Unión Europea}

mismo modo que el Derecho comunitario no es reconducible a ningún modelo clásico de sistema jurídico internacional o interno. A este respecto cabe destacar sobre todo el carácter obligatorio que tiene para los Estados miembros de la Comunidad la jurisdicción del Tribunal de Justicia sin ninguna exigencia adicional de consentimiento y sin ninguna posibilidad de limitaciones o reservas.

El impacto del Derecho comunitario en los sistemas jurídicos nacionales no es el resultado de decisiones caprichosas o arbitrarias del Tribunal de Justicia, en favor de una mayor integración. Se trata de decisiones coherentes con los principios que configuran el poder judicial comunitario, entre los que el mecanismo de la cuestión prejudicial tiene particular importancia. En efecto, la previsión de este mecanismo muestra bien a las claras la responsabilidad que los órganos jurisdiccionales asumen en la aplicación del Derecho comunitario. El Derecho comunitario se ha convertido así en un factor de expansión de la tutela jurisdiccional, dando lugar a una ampliación de los poderes de los órganos jurisdiccionales en algunos Estados miembros.

\section{El Derecho como factor de legitimación de la Unión Europea}

El Derecho ha sido tradicionalmente y continúa siendo el factor determinante de la legitimidad comunitaria: una legitimidad que encuentra su fundamento inmediato en los Tratados constitutivos -calificados por el Tribunal de Justicia como «carta constitucional de una comunidad de derecho" ${ }^{30}$, por analogía con la noción de Estado de derecho- y, por otra parte, un fundamento indirecto en los sistemas constitucionales de los Estados miembros, cada uno de los cuales hace posible la participación del respectivo Estado en el proceso de integración mediante las correspondientes transferencias de competencias a las instituciones comunes.

Pero si una legitimidad eminentemente jurídica podía resultar satisfactoria en relación con las exigencias de la llamada integración funcional (la Comunidad del Carbón y del Acero e incluso la Comunidad Económica Europea, cuyos objetivos estaban básicamente limitados al ámbito económico) esta legitimidad es percibida progresivamente como insuficiente en unos momentos en que la Unión Europea despliega una actividad cada vez más amplia y que incide de manera cada vez más directa en la vida de los ciudadanos. La Unión Monetaria, que supone un auténtico cambio cualitativo del proceso de integración, hace aún más perceptible esa insuficiencia. 


\section{Gil Carlos Rodríguez Iglesias}

Ahora bien, conviene precisar que el «déficit democrático» de la Unión Europea del que se habla recurrentemente hace referencia a la insuficiente legitimidad democrática directa del poder que se ejerce por las instituciones comunitarias.

En cambio, a mi juicio es inexacto negar sin matizaciones le legitimidad democrática de la Unión Europea.

Desde el punto de vista político, la legitimidad de la Unión Europea procede de los Estados y de los pueblos constituidos en Estados y no debe olvidarse que el "poder constituyente» - es decir la capacidad de modificar los Tratados constitutivos - sigue residiendo en los Estados miembros. Así a través del Derecho la Unión Europea también recibe una legitimidad democrática.

Los Tratados de Maastricht y Amsterdam no prefiguran desde luego todavía una auténtica Unión política, revestida de una legitimidad democrática directa, a pesar de la importancia de algunos cambios, entre los que hay que destacar especialmente la creación de la ciudadanía europea y el creciente papel del Parlamento Europeo.

Sin duda es necesario profundizar en la dimensión política de la Unión Europea. Sin embargo, ello no debe llevar a subestimar la importancia de la legitimación que resulta de la configuración de la Comunidad como una comunidad de derecho, legitimidad que debe fortalecerse aún más extendiendo el imperio del derecho que reina plenamente en el ámbito de las Comunidades Europeas a todo el ámbito de la Unión Europea.

\section{Notas}

1 Con la colaboración de Fernando CASTILLO DE LA TORRE, Letrado del Tribunal de Justicia de las Comunidades Europeas.

2 La proliferación de conceptos y expresiones dificultan considerablemente la compresión del proceso de integración por el ciudadano. Los elementos básicos del proceso han sido y siguen siendo las tres Comunidades europeas: la Comunidad Europea del Carbón y del Acero (CECA), creada por el Tratado de París de 1951, y las dos Comunidades creadas por el Tratado de Roma de 1957, la Comunidad Económica Europea (CEE) y la Comunidad Europea de la Energía Atómica (Euratom). La CEE, por su carácter general, es la más importante y, a partir del Tratado de Maastricht sobre la Unión Europea, de 1992, ha pasado a denominarse simplemente la Comunidad Europea. La perdida del calificativo "económica" subraya su vocación de Comunidad de integración general.

Junto a las Comunidades europeas - cuyo funcionamiento se ha basado fundamentalmente en instituciones comunes dotadas de una importante autonomía respecto a los Estados, lo que ha dado lugar a la calificación del sistema comunitario como un sistema "supranacional" - se ha desarrollado de forma complementaria una cooperación intergu- 


\section{La función del Derecho y del Juez en la Unión Europea}

bernamental en distintos ámbitos, entre los cuales destacan los llamados "pilares intergubernamentales": el "segundo pilar", la Política Exterior y de Seguridad Común (PESC) y el "tercer pilar", la Cooperación en asuntos de justicia e interior (actualmente, Cooperación judicial y policial en materia penal), calificativos que sólo se entienden si se tiene presente que el "primer pilar" es el "pilar comunitario", es decir, las tres Comunidades Europeas.

A partir del Tratado de Maastricht, tanto las Comunidades Europeas como los pilares intergubernamentales han quedado integrados en la Unión Europea, denominación que se aplica al conjunto y que se ha convertido en la más conocida y utilizada. La Unión Europea tiene un marco institucional único, pero las instituciones comunes tienen distintas competencias en cada uno de los "pilares" e incluso en las distintas Comunidades Europeas.

Los diferentes Tratados constitutivos de las Comunidades Europeas han sido modificados. Merecen destacarse las siguientes modificaciones: (1) el Acta Única Europea (1986, que entró en vigor en 1987); (2) el Tratado de Maastricht (de 7 de febrero de 1992, que entró en vigor el 1 de noviembre de 1993), que aparte de modificar los Tratados de las Comunidades crea la Unión Europea; (3) y el Tratado de Amsterdam (de 2 de octubre de 1997, que entró en vigor el 1 de mayo de 1999). Este último tratado modificativo ha establecido una nueva numeración de los artículos. En el presente trabajo se utilizará la nueva numeración, indicando entre paréntesis el antiguo número. De todos modos se ha tratado de reducir al mínimo la referencia a artículos de los Tratados.

Las siglas utilizadas en el presente artículo son: Tratado CEE (Tratado constitutivo de la Comunidad Económica Europea), Tratado CE (Tratado constitutivo de la Comunidad Europea), Tratado CECA (Tratado constitutivo de la Comunidad Europea del Carbón y del Acero), Tratado CEEA (Tratado constitutivo de la Comunidad Europea de la Energía Atómica), Tratado UE (Tratado de la Unión Europea). Conviene finalmente recordar que, desde la entrada en vigor del Tratado de Maastricht, el Tratado CEE se ha convertido en Tratado CE.

3 La mayoría de los elementos recogidos en el presente artículo han sido desarrollados más ampliamente en otros trabajos míos: “El Tribunal de Justicia de las Comunidades Europeas", en El Derecho comunitario y su aplicación judicial (dirigido por G.C. Rodríguez Iglesias y D.J. Liñán Nogueras), Civitas, 1993, p. 373; «La función del Tribunal de Justicia de las Comunidades Europeas y los rasgos fundamentales del ordenamiento jurídico comunitario", Foro internacional, 1993, p. 275; “El Derecho como instrumento de integración económica y monetaria en la Comunidad Europea" (en colaboración con M. López Escudero), en Libro Homenaje A. Menéndez, 1995, Civitas, p. 5405 ; “Le pouvoir judiciaire de la Communauté européenne au stade actuel de l'évolution de l'Union", Collected Courses of the Academy of European Law, 1996, vol. VII-1, págs. 33-57; "El Derecho comunitario y las relaciones entre el Tribunal de Justicia de las Comunidades Europeas, el Tribunal Europeo de Derechos Humanos y los Tribunales constitucionales nacionales", (en colaboración con Alejandro Valle Gálvez), Revista de derecho comunitario europeo, CEPC, n. 2, julio/diciembre 1997, págs. 329-376; “Die Bedeutung der Rechtsprechung des Europäisches Gerichtshofes für die Errichtung des Binnenmarkts" en J. Schwarze (Coor.) Unverfälschter Wettbewer für Arzneimittel im Europäischen Binnenmarkt, Nomos Verlag, Baden-Baden, 1998, págs. 9-21; "La dimensión constitucional del Derecho comunitario europeo", Discurso de ingreso como Académico honorario en la Academia Asturiana de Jurisprudencia, 1998.

4 El plan de integración comprende lo que Ophüls ha denominado una "planificación interna", contenida en cada Tratado, y cuyos objetivos son los específicos de cada Comu- 


\section{Gil Carlos Rodríguez Iglesias}

nidad, y una "planificación externa", referida al proceso global. La "planificación externa", no contenida en los tratados, es decir, la integración de los distintos tratados en un todo comprensivo y progresivo, sólo en parte está fijada jurídicamente; lo decisivo pertenece aún al ámbito de la reflexión política futura. Sin embargo, el núcleo dominante de este plan unitario que se expresa en los tres Tratados está sustancialmente contenido en cada uno de ellos: a) La idea básica de la renuncia progresiva a la soberanía; b) La integración económica como medio principal de conseguir esta evolución; c) Las mismas formas de las instituciones, que esencialmente actúan con los mismos procedimientos y con órganos idénticos o semejantes (C.F. Ophüls: “Los tratados constitutivos de las Comunidades Europeas como constitución y como plan", en Planificación, II, Madrid, 1974, pág. 236).

5 Sentencia de 12 de marzo de 1987, Comisión / Alemania, asunto 178/84, Rec. 1987, p. 1227.

6 Sentencia de 21 de junio de 1974 , asunto $2 / 74$, Rec. 631 .

7 Sentencia de 12 de diciembre de 1974, asunto 36/74, Rec. p. 1405.

8 Luisi y Carbone, asuntos acumulados 286/82 y 26/83, Rec. 1984, p. 377; Cowan, asunto 186/87, Rec. 1989 p. 195.

9 Sentencia de 12 de mayo de 1998, C-85/96, Rec. 1998, p. I-2691.

10 Cfr. A. Valle Gálvez, "La cohesión económica y social como objetivo de la Unión Europea. Análisis y perspectivas", Revista de Instituciones Europeas, 1994, págs. 345 y 346.

11 Vid. M. López Escudero, "La articulación jurídica de la Unión Económica y Monetaria en su fase definitiva", Revista de Derecho comunitario europeo, número 4, 1998, p. 389.

12 Resolución del Consejo Europeo de 17 de junio de 1997, sobre el Pacto de Estabilidad y Crecimiento (DO 1997 C 236, p. 1).

13 DO 1997, L 209, p. 1.

14 DO 1997, L 209, p. 6.

15 Sentencia de 5 de febrero de 1963, Van Gend en Loos, asunto 26/62, Rec. 1963 p. 3.

16 Sentencia de 15 de julio de 1964, Costa/Enel, asunto 6/64, Rec. p. 1141.

17 Sentencia de 9 de marzo de 1978, Simmenthal, asunto 106/77, Rec. 1978 p. 629.

18 Asuntos acumulados C-6 y C-9/90, Francovich y Bonifaci, Rec. 1991 p. I-5357.

19 Sentencia de 5 de marzo de 1996, C-46/93 y C-48/93, Rec. 1996 p. I-1029.

20 Me referiré principalmente a la Comunidad Europea o a las Comunidades Europeas puesto que la competencia del Tribunal de Justicia respecto a los pilares intergubernamentales que comprende la Unión es limitada, aunque ha sido ampliada por el Tratado de Amsterdam.

21 Decisión 88/591/CECA, CEE, Euratom, del Consejo (DO 1989, C 215, p. 1).

22 Sentencias de 4 de octubre de 1979, Francia/Reino Unido, asunto 141/78, Rec. 1979 , p. 2923, y de 16 de mayo de 2000, Bélgica/España, C-388/95.

23 En el Dictamen 1/91, sobre el Espacio Económico Europeo (Dictamen 1/91, de 14 de diciembre de 1991, Rec. p. I-6079) se reafirma la idea que “... el Tratado CEE, aunque haya sido celebrado en forma de Convenio Internacional, no por ello deja de ser la carta constitucional de una comunidad de derecho".

24 Sentencia de 15 de mayo de 1986, Johnston, asunto 222/84, Rec. 1986, p. 1651.

28 Sentencia de 15 de octubre de 1987, asunto 222/86, Rec. 1987, p. 4097, apartado 14 .

29 Es justo rendir homenaje a quien ha protagonizado el debate sobre esta cuestión en España, E. García de Enterría, a través de sus múltiples trabajos dedicados al estudio de la justicia cautelar, recogidos en su mayoría en La batalla por las medidas caute- 


\section{La función del Derecho y del Juez en la Unión Europea}

lares: Derecho comunitario europeo y proceso contencioso-administrativo español, segunda edición ampliada, Madrid, Civitas, 1995.

27 Factortame I, asunto C-213/89, Rec. 1990, p. I-2433.

28 Sentencia de 21 de febrero de 1991, Zuckerfabrik, asuntos acumulados C-143/88 y C-92/89, Rec. p. I-0415.

29 Auto de la Sala Tercera del Tribunal Supremo de 20 de diciembre de 1990, comentado por E. García de Enterría, op. cit., p. 157-188.

30 Sentencia de 23 de abril de 1986 "Les Verts" c. Parlamento Europeo, asunto 294/83, Rec. p. 1339 y Dictamen 1/91 de 14 de diciembre de 1991, Rec. p. I-6079. 